\title{
ASSESSMENT OF MAINTENANCE NEEDS REQUIRED TO PRESERVE THE OPERATIONAL STATUS OF COMBAT VEHICLES PARTICIPATING IN MILITARY OPERATIONS
}

\author{
Vasile CĂRUŢAŞU, Daniela CĂRUŢAŞU \\ "Nicolae Bălcescu” Land Forces Academy, Sibiu, Romania
}

\begin{abstract}
An important step in preparing a military operation is the planning one where resource requirements and related costs are assessed needed to conduct it under optimal conditions. One of the most important issues to be considered at this stage is that concerning the means of warfare which are necessary for fulfilling the tasks of the military operation. In this regard both the types of combat capabilities that are required and the number of each type of combat capabilities should be established. After evaluating the necessary means of combat, an important aspect to be considered is that of ensuring the maintenance service for the means of combat planned to participate in military operations. In this study, based on technical specifications related to maintenance operations to be carried out to maintain the operational state of combat means is shown, depending on the tasks to be fulfilled within the military operation, a way of assessing maintenance needs in order to design a plan to ensure optimal maintenance service.
\end{abstract}

Keywords: assessment model, military operation, optimum maintenance plan, technical specifications

\section{Introduction}

This study presents a method for assessing maintenance operations to be carried out to maintain the operational state of combat means to achieve the optimal use of all planned missions within a military operation.

More specifically we will present a way of assessing the number of the maintenance teams necessary to perform maintenance operations for all types of combat vehicles intended for the military operation, depending on the characteristics of its missions.

This assessment allows us to get an insight into spatial planning needs to be organized for the maintenance service, for the equipment and personnel involved in performing these operations

Also, this assessment allows the estimation of costs related to the maintenance service organization and the maintenance of combat means during the conduct of the military operation.

2. Parameters for the Conduct of the Military Operation

In this section we will resume some of the elements related to establishing the conditions under which the military operation is conducted and the tasks to be fulfilled within it, issues that are also described in papers [1], [2] or [3]. 
The table below contains a summary, according to the regulations stipulated in [4], data relating to the number of vehicles of each type destined for conducting the military operation, number of vehicles of each type necessary to meet each of the $n$ tasks, the distances that vehicles must go across within each mission, the period of development of the military operation and the working time for the maintenance structure daily.

Table no. 1 General data of the military operation

\begin{tabular}{|c|c|c|c|c|c|}
\hline Type of vehicle & 1 & 2 & $\cdots$ & $n$ & $\begin{array}{c}\text { No. of vehicles } \\
\text { available }\end{array}$ \\
\hline Car & $a_{1}$ & $a_{2}$ & $\ldots$ & $a_{n}$ & $a$ \\
\hline Truck & $A_{1}$ & $A_{2}$ & $\ldots$ & $A_{n}$ & $A$ \\
\hline Armored transporter & $\operatorname{Tr}_{1}$ & $T r_{2}$ & $\ldots$ & $T r_{n}$ & $T r$ \\
\hline Tank & $T a_{1}$ & $T a_{2}$ & $\ldots$ & $T a_{n}$ & $T a$ \\
\hline \multicolumn{6}{|c|}{ More information about the military operation } \\
\hline Mission & 1 & 2 & $\ldots$ & $n$ & - \\
\hline Distance & $d_{1}$ & $d_{2}$ & $\ldots$ & $d_{n}$ & - \\
\hline Progress period & \multicolumn{5}{|c|}{$T$} \\
\hline $\begin{array}{l}\text { Working period for a maintenance } \\
\text { structure / day }\end{array}$ & \multicolumn{5}{|c|}{$t$} \\
\hline
\end{tabular}

In what follows, according to the regulations stipulated in [5] and [6], the information on the number of $\mathrm{km}$ each type of maintenance operation should be performed at and the duration of these maintenance operations are presented.
In this same table the number of lower-level maintenance operations which are performed are listed to the higher level ones, without taking into account the lower level operations included in the top level ones.

Table no. 2 Data concerning maintenance operations

\begin{tabular}{|l|c|c|c|c|}
\hline \multicolumn{1}{|c|}{ Type of vehicle } & Car & Truck & $\begin{array}{l}\text { Armored } \\
\text { transporter }\end{array}$ & Tank \\
\hline As. maintenance & 2500 & 15000 & 5000 & 1000 \\
\hline Level 1 Maint. Op. (km) & 10000 & 75000 & 15000 & 5000 \\
\hline Level 2 Maint. Op. (km) & 30000 & 150000 & 45000 & 10000 \\
\hline Level 3 Maint. Op. (km) & 10 & 15 & 20 & 20 \\
\hline Level 1 Maint. Op. (hours) & 70 & 90 & 130 & 110 \\
\hline Level 2 Maint. Op. (hours) & 90 & 110 & 170 & 180 \\
\hline Level 3 Maint. Op. (hours) & $n_{a}^{13}=7$ & $n_{A}^{13}=5$ & $n_{T r}^{13}=5$ & $n_{T a}^{13}=5$ \\
\hline $\begin{array}{l}\text { No. of level 1 maint.op. 1 to level 3 } \\
\text { maint.op. }\end{array}$ & $n_{a}^{12}=3$ & $n_{A}^{12}=4$ & $n_{T r}^{12}=2$ & $n_{T a}^{12}=4$ \\
\hline $\begin{array}{l}\text { No. of level 1 maint.op. 1 to level 2 } \\
\text { maint.op. }\end{array}$ & $n_{a}^{23}=2$ & $n_{A}^{23}=1$ & $n_{T r}^{23}=2$ & $n_{T a}^{23}=1$ \\
\hline $\begin{array}{l}\text { No. of level 1 maint.op. 2 to level 3 } \\
\text { maint.op. }\end{array}$ & \multicolumn{2}{|}{} \\
\hline
\end{tabular}

These parameters are useful in assessing the number of each type of maintenance operations to be performed on average for each type of combat means, and the average 
number of hours of their proper maintenance during the performance of military operations.

\section{Evaluation of the Average Number of Maintenance Hours for Every Type of Combat Vehicle}

The number of maintenance operations, their type and therefore corresponding maintenance hours are related to the number of kilometers covered, and in this sense we must evaluate the average number of kilometers that will be covered by each category of vehicle in order to fulfill the $n$ missions within the military operation.

Likewise, given [1], [2] or [3], where the assumption that all the vehicles destined for the military operation are operational throughout its duration on the one hand was made, and on the other hand that they are distributed in a balanced manner for the fulfillment of the $n$ missions, in the table below the average number of kilometers a vehicle in each category performs for the fulfillment of the $n$ missions within the military operation is presented.

Table no. 3 Data regarding the average number of $\mathrm{km}$ to be covered within the $n$ missions

\begin{tabular}{|l|l|c|}
\hline Type of vehicle & $\begin{array}{c}\text { No. of km covered by each category } \\
\text { of vehicles }\end{array}$ & $\begin{array}{c}\text { Average no. of km covered by each } \\
\text { category of vehicles }\end{array}$ \\
\hline Car & $K_{a}=d_{1} \cdot a_{1}+d_{2} \cdot a_{2}+\ldots+d_{n} \cdot a_{n}$ & $M K_{a}=\frac{K_{a}}{a}$ \\
\hline Truck & $K_{A}=d_{1} \cdot A_{1}+d_{2} \cdot A_{2}+\ldots+d_{n} \cdot A_{n}$ & $M K_{A}=\frac{K_{A}}{A}$ \\
\hline $\begin{array}{l}\text { Armored } \\
\text { transporter }\end{array}$ & $K_{T r}=d_{1} \cdot T r_{1}+d_{2} \cdot T r_{2}+\ldots+d_{n} \cdot T r_{n}$ & $M K_{T r}=\frac{K_{T r}}{T r}$ \\
\hline Tank & $K_{T a}=d_{1} \cdot T a_{1}+d_{2} \cdot T a_{2}+\ldots+d_{n} \cdot T a_{n}$ & $M K_{T c}=\frac{K_{T c}}{T c}$ \\
\hline
\end{tabular}

Based on these we can determine the average number of level 3 maintenance operations, the average number of level 2 maintenance operations and the average number of level 1 maintenance operations that must be performed for a vehicle in each category upon completion of the military operation that we will note with $N_{i}^{3}, N_{i}^{2}$ and $N_{i}^{1}, \quad$ respectively, where $i \in\{a, A, T r, T a\}$, considering the new values $n_{i}^{3}, n_{i}^{2}$ and $n_{i}^{1}$, respectively, where $i \in\{a, A, T r, T a\}$ of the number of lower-

$$
N_{a}^{3}=\left[\frac{M K_{a}}{30.000}\right]
$$

level maintenance operations included in the higher-level ones given in table no. 2, where by [ ] we note the integer part of a real number.

The average number of interventions for a vehicle of each type and for the three types of maintenance operations is determined just as in [1], [2] or [3], it's just that the values will be different from those in the papers mentioned.

Thus, for cars, the relations according to which we can determine the average number of level 3, 2 and 1 interventions are: 


$$
\begin{aligned}
& N_{a}^{2}=\left[\frac{M K_{a}-30.000 \cdot N_{a}^{3}}{10.000}\right]+N_{a}^{3} \cdot n_{a}^{23} ; \\
& N_{a}^{1}=\left[\frac{M K_{a}-30.000 \cdot N_{a}^{3}-10.000 \cdot N_{a}^{2}}{2.500}\right]+N_{a}^{2} \cdot n_{a}^{12}+N_{a}^{3} \cdot n_{a}^{13} .
\end{aligned}
$$

For trucks, the relations according to which we can determine

the average number of level 3, 2 and 1 interventions are:

$$
\begin{aligned}
& N_{A}^{3}=\left[\frac{M K_{A}}{150.000}\right] ; \\
& N_{A}^{2}=\left[\frac{M K_{A}-150.000 \cdot N_{A}^{3}}{75.000}\right]+N_{A}^{3} \cdot n_{A}^{23} ; \\
& N_{A}^{1}=\left[\frac{M K_{A}-150.000 \cdot N_{A}^{3}-75.000 \cdot N_{A}^{2}}{15.000}\right]+N_{A}^{2} \cdot n_{A}^{12}+N_{A}^{3} \cdot n_{A}^{13} .
\end{aligned}
$$

For armored transporters, the relations according to which we can determine the

average number of level 3, 2 and 1 interventions are:

$$
\begin{aligned}
& N_{T r}^{3}=\left[\frac{M K_{T r}}{45.000}\right] ; \\
& N_{T r}^{2}=\left[\frac{M K_{T r}-45.000 \cdot N_{T r}^{3}}{15.000}\right]+N_{T r}^{3} \cdot n_{T r}^{23} ; \\
& N_{T r}^{1}=\left[\frac{M K_{T r}-45.000 \cdot N_{T r}^{3}-15.000 \cdot N_{T r}^{2}}{5.000}\right]+N_{T r}^{2} \cdot n_{T r}^{12}+N_{T r}^{3} \cdot n_{T r}^{13} .
\end{aligned}
$$

For tanks, the relations according to which we can determine

the average number of level 3,2 and 1 interventions are:

With the help of these relations we will determine, just as in [1] or [2], the average number of maintenance hours required for each category of vehicles, which are given in the table below. 
Table No. 4 The average number of hours of maintenance for a vehicle during the conduct of the military operation

\begin{tabular}{|l|l|}
\hline Type of vehicle & \multicolumn{1}{|c|}{ Maintenance hours } \\
\hline Car & $O_{a}=N_{a}^{3} * 90+N_{a}^{2} * 70+N_{a}^{1} * 10$ \\
\hline Truck & $O_{A}=N_{A}^{3} * 130+N_{A}^{2} * 90+N_{A}^{1} * 15$ \\
\hline $\begin{array}{l}\text { Armored } \\
\text { transporter }\end{array}$ & $O_{T r}=N_{\mathrm{Tr}}^{3} * 170+N_{\mathrm{Tr}}^{2} * 130+N_{\mathrm{Tr}}^{1} * 20$ \\
\hline Tank & $O_{T a}=N_{T a}^{3} * 180+N_{T a}^{2} * 110+N_{T a}^{1} * 20$ \\
\hline
\end{tabular}

In order to establish the optimal plan of organization of the maintenance service we will calculate, just as in [1] or [2], the average number of revisions for a vehicle of each type, as can be seen in the table below, with the specification that these values will be different from those in the above mentioned works.

Table no. 5 The average number of revisions for a vehicle during the conduct of the military operation

\begin{tabular}{|c|c|}
\hline Car & $N_{a}=N_{a}^{3}+N_{a}^{2}+N_{a}^{1}$ \\
\hline Truck & $N_{A}=N_{A}^{3}+N_{A}^{2}+N_{A}^{1}$ \\
\hline $\begin{array}{c}\text { Armored } \\
\text { transporter }\end{array}$ & $N_{T r}=N_{\mathrm{Tr}}^{3}+N_{\mathrm{Tr}}^{2}+N_{\mathrm{Tr}}^{1}$ \\
\hline Tank & $N_{T a}=N_{\mathrm{Ta}}^{3}+N_{\mathrm{Ta}}^{2}+N_{\mathrm{Ta}}^{1}$ \\
\hline
\end{tabular}

For the determination of the optimum number of maintenance structures necessary to ensure the interventions to the combat equipment in order to conduct the military operation under good conditions, we will calculate the average rate of arrival for maintenance of a vehicle (regardless of its type) and the average rate of servicing for a maintenance structure depending on the number of daily working hours. The relations with the help of which we calculate these parameters are similar to those in papers [1] and [2], but with the difference that $N_{a}, N_{A}, N_{T r}$ and $N_{T a}$ are different from those in the papers mentioned.

For the average rate of arrival of a vehicle for maintenance first we have to determine the total number of maintenance interventions for all the vehicles:

$N_{T}=N_{a} \cdot a+N_{A} \cdot A+N_{T r} \cdot T r+N_{T a} \cdot T a$
Based on that we can determine the average rate of arrival of vehicles for maintenance which is:

$$
\lambda=\frac{N_{T}}{T} .
$$

In order to calculate the average rate of servicing for a maintenance structure we must first determine the total hours of maintenance for all vehicles and for the fulfillment of all the missions within the military operation:

$O_{T}=O_{a}^{T} \cdot a+O_{A}^{T} \cdot A+O_{T r}^{T} \cdot T r+O_{T a}^{T} \cdot T a$.

Hence

$t_{\text {ment }}=\frac{O_{T}}{T}$

is the average daily time required for vehicle maintenance and then the average rate of servicing is:

$\mu=\frac{t}{t_{\text {ment }}}$.

With this information we can establish the 
optimal number of maintenance structures: $N_{\text {ment }}=\left[\frac{\lambda}{\mu}\right]+1$.

time in the system for a vehicle in order to execute maintenance works. The result:

Here we also calculate the average queuing

$$
\begin{aligned}
& W_{s}=\frac{1}{\mu-\lambda}, \text { if } N_{\text {ment }}=1 \text { and } \\
& \mathrm{W}_{\mathrm{s}}=\frac{1}{\mu}+\frac{1}{\lambda} \cdot \frac{\rho^{N_{\text {ment }}}}{\left(N_{\text {ment }}-1\right) ! \cdot\left(N_{\text {ment }}-\rho\right)^{2}} \cdot\left[\sum_{i=0}^{N_{\text {ment }}-1} \frac{\rho^{i}}{i !}+\frac{\rho^{N_{\text {ment }}}}{N_{\text {ment }} ! \cdot\left(1-\frac{\rho}{N_{\text {ment }}}\right)}\right]^{-1} \text {, if } N_{\text {ment }}>1,
\end{aligned}
$$

where $\rho=\frac{\lambda}{\mu}$.

Based on these pieces of information we can obtain The Optimal Plan of Organization of the Maintenance Service for the equipment necessary for the conduct of the military operation.

\section{Conclusion}

Although this study is conducted only for 4 types of combat means it can extend to any number of types of combat means, provided that we have their technical data.

Obviously, in such an analysis, we can consider a certain percentage of the total number of interventions and hours of maintenance for operations that are unscheduled, but necessary in order to maintain the operational state of combat means.

Additionally, based on this study the computer application presented in [1] or [2] was improved, application which establishes The Optimal Plan for the Organization of the Maintenance Service for the realization of maintenance operations according to the data sheets of the combat means and can be correlated with the information obtained in [3].

\section{References}

[1] Căruţaşu, D., The Use of Modeling and Simulation in the Design of Weapon Systems within the Land Forces, Sibiu, "Nicolae Bălcescu" Land Forces Academy Publishing House, 2014

[2] Căruţaşu, V., Modeling and Simulation of the Decision-Making Process in the Military Field, Sibiu, "Nicolae Bălcescu" Land Forces Academy Publishing House, 2014

[3] Căruţaşu, V., Căruţaşu, D., Estimates of the Number of Products and Spare Parts Necessary to Maintain the Operational Status of the Combat Vehicles Participating in the Conduct of Military Operations, Land Forces Academy Review, No. 4(76), 2014

[4] ***, NATO Land Forces Logistic Doctrine, ALP-9(c), STANAG 2406

[5] ***, FT/Au - 4/1 - The Maintenance Platoon Commander's Guide, Piteşti, 2005

[6] ***, L 11 - Instructions on the Maintenance of Equipment in the Endowment of the Ministry of National Defense in Peacetime, in Crisis Situations and in Wartime, Bucharest, 2002 